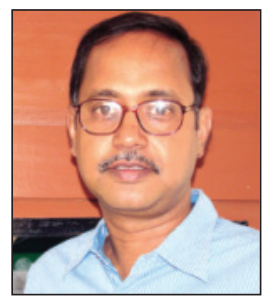

JOURNAL OF MINES, METALS \& FUELS www.jmmf.info

Jayanta Bhattacharya

Hony. Chief Editor

\title{
Reimagining mined landscape for various new purposes: bringing life back to the derelict sites
}

All over the world various mined landscapes are left deserted with a few or sometimes many infrastructures still breathing in some life.There has not been much concerted thinking as to how such infrastructure can be reused or repurposed. To list some infrastructure commonly found in the closed mine sites are boundary walls, offices, roads, water and electricity connections, vehicles and equipment. The mining company after announcing that the mineable resource stands exhausted, either leave the property as it is or returns to the states, with or without the obligation of reclamation or closure. And in many cases, the bankrupt state of the region would not have the capacity and capability to execute something purposeful in that place. But this is how it should not have to be. One major impediment is legality. The character of the mine lease entails that the mining company only has the mining rights on the land as long as there is some minerals to mine, and once the resources are exhausted, the company does not have any other rights on the land. The leasehold area, which is also called mine in some nomenclature, ceases to be a mine and has to be returned to be returned to the original title of farm or habitable land, as existed before the mine started, for example. Now if the mined land is made accessible to the mining company or to a new owner under a suitable arrangement the infrastructure can be gainfully used and new investment can bring back the mined land or a part of it, to new life. In the below we shall know an example of repurposing of mined lands are taking place around us. We cite glimpses of a comprehensive uranium tailings management area has been repurposed into a nature sanctuary and passive recreational setting, the Sherriff Creek Wildlife Sanctuary, in Ontario, Canada. The results demonstrate that the repurposing mechanism benefits

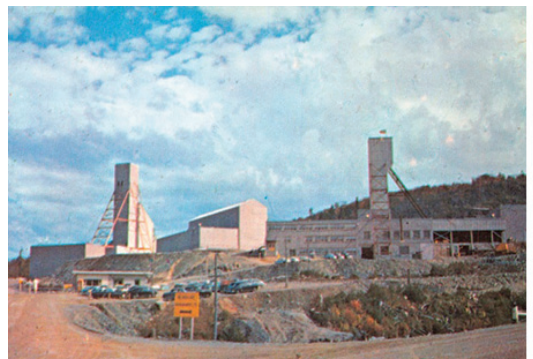

The Milliken

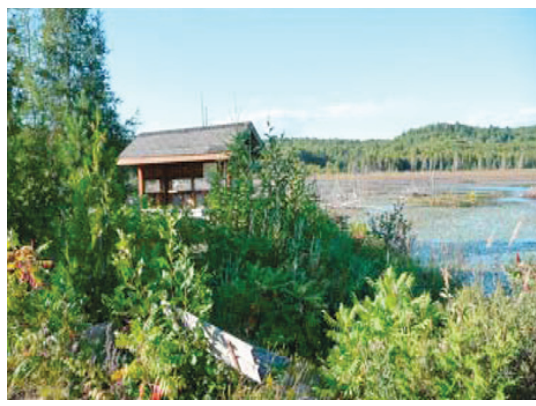

Bird watching spot near a creek before the tailing pond

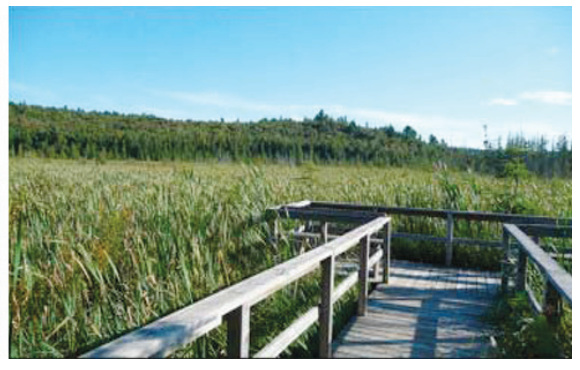

The tailing pond made into biodiversity habitat

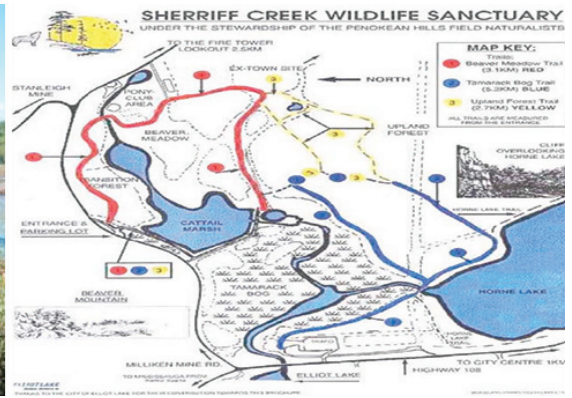

economic transition by enhancing local development paths (both emerging and branching innovating). These benefits, studies show, arise from a neo-endogenous approach that combines a local drive to implement repurposing, with the enabling capital of an external partner. New examples are being reported from all over the world.

Reference: Clare J. A. Mitchell and Kendra O'Neill, “The Sherriff Creek Wildlife Sanctuary: Further evidence of mine-site repurposing and economic transition in northern Ontario". The Journal of The Extractive Industries and Society, 10 January 2017. 